\title{
A detrimental role of RelB in mature oligodendrocytes during experimental acute encephalomyelitis
}

\author{
Angela S. Gupta', Debolina D. Biswas', La Shardai N. Brown¹, Karli Mockenhaupt ${ }^{1}$, Michael Marone', \\ Andrew Hoskins', Ulrich Siebenlist ${ }^{2}$ and Tomasz Kordula ${ }^{1 *^{*}}$ (1)
}

\begin{abstract}
Background: Multiple sclerosis (MS) is an autoimmune demyelinating disease of the central nervous system (CNS). It is firmly established that overactivation of the p65 (RelA) nuclear factor kappa B (NF-kB) transcription factor upregulates expression of inflammatory mediators in both immune and non-immune resident CNS cells and promotes inflammation during MS. In contrast to p65, NF-KB family member RelB regulates immune cell development and can limit inflammation. Although RelB expression is induced during inflammation in the CNS, its role in MS remains unknown.

Methods: To examine the role of RelB in non-immune CNS cells, we generated mice with RelB specifically deleted in astrocytes (RelB ${ }^{\Delta A S T}$ ), oligodendrocytes (RelB ${ }^{\Delta O L I G O}$ ), or neural progenitor-derived cells (RelB ${ }^{\Delta N P}$ ). We used experimental autoimmune encephalomyelitis (EAE), an accepted mouse model of MS, to assess the effect of RelB deletion on disease outcomes and performed analysis on the histological, cellular, and molecular level.

Results: Despite being a negative regulator of inflammation, conditional knockout of RelB in non-immune resident CNS cells surprisingly decreased the severity of EAE. This protective effect was recapitulated by conditional deletion of RelB in oligodendrocytes but not astrocytes. Deletion of RelB in oligodendrocytes reduced disease severity, promoted survival of mature oligodendrocytes, and correlated with increased activation of p65 NF-kB.

Conclusions: These findings suggest that RelB fine tunes inflammation and cell death/survival during EAE. Importantly, our data points out the detrimental role RelB plays in controlling survival of mature oligodendrocytes, which could be explored as a viable option to treat MS in the future.
\end{abstract}

Keywords: EAE, Inflammation, RelB, Oligodendrocytes, Astrocytes, NF-KB

\section{Background}

Multiple sclerosis (MS) is a chronic inflammatory autoimmune demyelinating disease of the central nervous system (CNS) that manifests with symptoms such as muscle weakness, impaired motor skills and coordination, and sensory loss. Although the primary cause of the disease is not known, demyelination, primarily mediated by $\mathrm{T}$ cells that are reactive to myelin antigens,

\footnotetext{
* Correspondence: Tomasz.Kordula@vcuhealth.org

${ }^{1}$ Department of Biochemistry and Molecular Biology, Virginia Commonwealth University, School of Medicine and the Massey Cancer Center, Richmond, VA 23298, USA

Full list of author information is available at the end of the article
}

and ongoing inflammation are believed to cause damage to the CNS. MS lesions are commonly characterized by apoptotic loss of oligodendrocytes, loss of myelin-associated glycoproteins, immune cell infiltration, activation of resident glial cells, and axon degeneration [1, 2].

Ubiquitously expressed transcription factors of the nuclear factor kappa B (NF-kB) family regulate many cellular processes, including cell proliferation and survival, production of inflammatory mediators, differentiation of $\mathrm{T}$ cells, and maturation of dendritic cells $[3,4]$. NF- $\mathrm{kB}$ family consists of five members: p65 (RelA), RelB, c-Rel, p50/p105, and p52/p100 that can form a variety of homoand heterodimers. Under resting conditions, NF- $\mathrm{kB}$

(C) The Author(s). 2019 Open Access This article is distributed under the terms of the Creative Commons Attribution 4.0 International License (http://creativecommons.org/licenses/by/4.0/), which permits unrestricted use, distribution, and 
proteins are sequestered in the cytoplasm to prevent aberrant activation. A typical inflammatory stimulus activates the canonical NF- $\mathrm{kB}$ pathway triggering degradation of in-

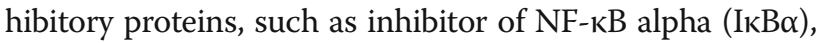
translocation of p65/p50 heterodimers to the nucleus, and induction of p65/p50-dependent genes [5]. It is now firmly established that overactivation of p65 in immune cells contributes to inflammation in MS. There is an increased nuclear localization of p65 in microglia and macrophages in active lesions of human MS patients [6]. Accordingly, an increased p65 DNA binding has been reported in rat spinal cords during experimental autoimmune encephalomyelitis (EAE), which is a rodent model of MS $[6,7]$. Furthermore, microarray studies have demonstrated increased expression of NF- $\mathrm{kB}$ proteins in MS patients [8]. Conversely, preventing degradation of $\mathrm{I} \mathrm{KB} \alpha$ decreases the incidence and severity of EAE by decreasing antigenspecific T cell responses [9]. c-Rel, which is a target of the canonical NF-kB pathway, is also crucial for the development of EAE, and c-Rel knockout mice are completely protected from the disease. c-Rel knockout mice are characterized by decreased numbers of Th17 and Th1 autoreactive $\mathrm{T}$ cells [10].

In contrast to p65, RelB is mostly known as a target of the non-canonical NF- $\mathrm{kB}$ pathway, which is triggered by specific ligands that control development of lymphoid tissues [11]. These ligands induce processing of p100 to p52 and subsequent translocation of RelB/p52 heterodimers to the nucleus [12]. Interestingly, in the presence of high RelB expression [13], RelB/p50/IkB $\alpha$ complexes form and are activated by the canonical pathway $[13,14]$, but this is limited since RelB has higher affinity for p100/p52 than for p50 [15]. The crucial function of RelB in regulating immunity is best exemplified through knockout animal models. RelB knockout mice have a shorter lifespan and severe autoimmunity $[11,16,17]$. Because RelB plays a crucial role in immune cell development, particularly dendritic cells, RelB knockout mice lack Peyer's patches, germinal centers, and dendritic cell networks [12, 18]. Furthermore, its loss results in a lack of negative $\mathrm{T}$ cell selection, and thus severe multiorgan inflammation with both $\mathrm{T}$ cell and monocytic infiltrates [19]. Nevertheless, RelB can also repress p65 activity through multiple mechanisms [20-24], which provides a negative feedback loop suppressing cytokine and chemokine expression. Indeed, RelB has been implicated in establishing tolerance in macrophages during septic shock [22]. We have recently shown that RelB also limits cytokine expression in astrocytes, which limits neuroinflammation [24]. Although RelB plays a crucial role in inflammation and immune cell development, its role has not been studied in animal models of MS.

While peripheral and local immune cells are central to the pathogenesis of MS, it is now evident that resident non-immune CNS cells are also critical. Indeed, activation of astrocytes during MS is an important process that directly contributes to the pathology of the disease [25-27]. NF-кB signaling is highly activated in reactive astrocytes and modulates expression of inflammatory mediators, cell death, and cell survival. Accordingly, overexpression of dominant-negative IкB $\alpha$ in astrocytes, which inhibits canonical NF- $\mathrm{KB}$ signaling, decreases EAE severity [28]. Multiple intrinsic signaling cascades also modulate susceptibility of oligodendrocytes to injury and thus disease severity [29-31]. Blocking p65 activation in oligodendrocytes has recently been found to increase oligodendrocyte death and reduce remyelination [32]. Although it is evident that p65 plays an important role in non-immune cells of the CNS during MS, the role of RelB has not been investigated. RelB is expressed at low levels in astrocytes [14, 24], but its expression is increased in astrocytes during EAE [21]. Since RelB suppresses cytokine expression in astrocytes and thus regulates neuroinflammation [24], we asked whether RelB in non-immune CNS cells modulates severity of EAE. Understanding the role of RelB in the pathogenesis of MS could provide clues for future therapeutic approaches.

\section{Materials and methods \\ Mice}

Mice with the RelB allele flanked by loxP sites generated by Dr. Ulrich Sibienlist (NIH) were bred with GFAP-Cre (Jackson Laboratory) to generate RelB astrocyte-specific conditional knockout mice (RelB ${ }^{\triangle A S T}$ ), nestin-Cre (Jackson Laboratory) to generate RelB neural progenitor-specific conditional knockout mice $\left(\operatorname{RelB}^{\Delta \mathrm{NP}}\right)$, and CNPase-Cre (from Dr. X. Li, Cleveland Clinic, Cleveland, OH) to generate RelB oligodendrocyte-specific knockout mice $\left(\operatorname{RelB}^{\Delta \mathrm{O}-}\right.$

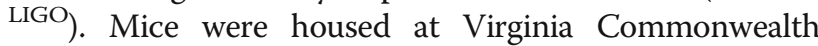
University according to guidelines of the Institutional Animal Care and Use Committee. The mouse protocols were approved by the Institutional Animal Care and Use Committee. Animals were housed in the animal facility, with a 12-h light/dark cycle, and provided water and standard laboratory chow ad libitum. Randomly chosen littermates (males and females) were used for all experiments. All animals were included for data analysis unless they reached a set humane endpoint ( $20 \%$ weight loss) before the end of experiment. The group sizes for each experiment are provided in figure legends. The disease progress was recorded for all experimental animals, while molecular analysis was performed in smaller animal groups that were analyzed using statistics. To establish statistical significance, data were analyzed by ANOVA (multiple comparisons) and both $\mathrm{F}$ and $p$ values are indicated in the figure legends. Furthermore, post-hoc Sidak's test was used for these multiple comparisons ( $p$ values from Sidak's tests are also indicated). For comparisons of 
two groups, data were analyzed by $T$ test and both $F$ and $p$ values are indicated in the figure legends. Asterisk designates statistical significance with both $F$ and $p$ values indicated.

\section{Experimental autoimmune encephalomyelitis}

Each mouse received subcutaneous $200 \mu \mathrm{g}$ MOG35-55 peptide (AnaSpec) emulsified in CFA containing $500 \mu \mathrm{g}$ Mycobacterium tuberculosis H37Ra (Difco, Detroit, MI) and intraperitoneal $200 \mathrm{ng}$ pertussis toxin (Enzo Life Sciences, Farmingdale, NY). A booster dose of 200 ng pertussis toxin was administered 2 days after immunization. Mice were clinically scored and weighed daily, and the severity of the disease was quantified using a five-point scale: 0 , no symptoms; 1 , limp tail; 2 , limp tail with loss of righting; 3, paralysis of single hind limb; 4, paralysis of both hind limbs; and 5, death. Two-three independent experiments were performed (as indicated in figure legends), and cumulative data are presented. Tissues were collected at day 15 from PBS- and MOG-injected animals for molecular/cellular analysis.

\section{Cell culture}

To prepare mouse cortical astrocytes, cerebral cortices were aseptically dissected and meninges were removed. Tissue was mechanically dissociated, incubated with trypsin and DNaseI at $37{ }^{\circ} \mathrm{C}$ for $30 \mathrm{~min}$, and centrifuged. Tissue was filtered through a $70 \mu \mathrm{m}$ filter and re-centrifuged. Cells were resuspended and plated in dishes pre-coated with poly-D-lysine. Cells were cultured in Dulbecco's modified Eagle's medium supplemented with $10 \%$ fetal bovine serum, penicillin/streptomycin, sodium pyruvate, and non-essential amino acids.

\section{Western blotting}

Cells or ground flash frozen tissue were lysed in $10 \mathrm{mM}$ Tris (pH 7.4), $150 \mathrm{mM}$ sodium chloride, $1 \mathrm{mM}$ EDTA, 1\% Nonidet P-40, 1\% Triton X-100, $1 \mathrm{mM}$ sodium orthovanadate, $0.2 \mathrm{mM}$ PMSF, and Pierce protease inhibitor mixture. Samples were separated on a $10 \%$ gel and transferred onto nitrocellulose membranes (GE Healthcare). Anti- $\beta$-tubulin (sc-9104), anti-RelB (sc-226), anti-p65 (sc-372) antibodies (Santa Cruz Biotechnology); anti-GAPDH (5174); and anti-phospho-p65(S536) (3031) antibodies (Cell Signaling) were used. Antigen-antibody complexes were visualized by enhanced chemiluminescence using Immobilon Western blotting kit (Millipore).

\section{Quantitative PCR}

Total RNA was prepared from flash frozen tissue with Trizol (Life Technologies), reverse transcribed with the high-capacity cDNA kit (Applied Biosystems), and amplified on the BioRad CFXConnect Real-time System. SYBR Green intron-spanning pre-design qPCR primers
(BioRad) were used. Gene expression levels were normalized to GAPDH and represented as fold expression over control.

\section{Immunofluorescence}

Animals were perfused with $4 \%$ paraformaldehyde, tissue was embedded in optimal cutting medium, and $40 \mu \mathrm{m}$ frozen sections were prepared. For fluoromyelin staining, slides were rehydrated in PBS for $20 \mathrm{~min}$ and then flooded with 1:300 diluted stain for $20 \mathrm{~min}$. Counterstaining was done using Hoechst stain for $5 \mathrm{~min}$, and slides were mounted using vectashield mounting medium (Vector Laboratories). Slides were imaged using the Zeiss LSM 700. For antibody staining, sections were incubated with primary anti-RelB, anti-GFAP, anti-p65, anti-phospho-p65 (all 1:300, Cell Signaling), anti-CC1 (1:200, Millipore), or anti-Iba1 (1:500, Wako) antibodies overnight at $4{ }^{\circ} \mathrm{C}$. Subsequently, sections were incubated with Alexa Fluor 488 or Alexa Fluor 594 secondary antibodies (1:500, Invitrogen) for $1 \mathrm{~h}$ at room temperature. Slides were mounted and imaged as described above. No fluorescence crossover was found between the channels, and images were collected separately using the appropriate laser excitation. Images were analyzed using ImageJ.

\section{Immunohistochemistry}

Animals were perfused with $4 \%$ paraformaldehyde and tissue was paraffin-embedded, sectioned, and H\&Estained at the Cancer Mouse Models Core Facility (VCU, Richmond, VA). Slides were imaged using the Zeiss AxioImager A1 as indicated. Infiltration of immune cells was quantified by counting immune cells in the peripheral regions of the spinal cords.

\section{Isolation and analysis of immune cells in the CNS}

Brains from the mice were dissociated using Wheaton Dounce glass tissue grinders, strained through $70 \mu \mathrm{m}$ filter, and subjected for centrifugation at $1500 \mathrm{rpm}$ for $5 \mathrm{~min}$ at $4{ }^{\circ} \mathrm{C}$. Pelleted cells were resuspended in $10 \mathrm{ml}$ of $30 \%$ Percoll (Amersham Bioscience) and centrifuged onto a 70\% Percoll for $30 \mathrm{~min}$ at $2600 \mathrm{rpm}$. Cells were collected at the $30-70 \%$ interface and stained with fluorescence-conjugated monoclonal antibodies against CD45 (clone 30-F11), CD11b (clone M1/70), CD4 (clone GK 1.5), CD8 (clone 53-6.7), and isotype control antibodies (Biolegend) were used to analyze cells.

\section{Statistical analysis}

Statistical analysis was performed using GraphPad Prism 7. Values are displayed as mean \pm standard error. $T$ tests and ANOVAs were performed as indicated. Post-hoc Sidak's was used for multiple comparisons. 


\section{Results}

Deletion of RelB in non-immune CNS cells reduces severity of EAE

Since RelB is upregulated in astrocytes during both EAE [33] and experimental LPS-induced neuroinflammation [24] and limits astrocytic cytokine production [24], we predicted that it may play important functions in non-immune CNS cells during $\mathrm{EAE}$, and its deletion may exaggerate severity of the disease. To test this hypothesis, we crossed nestin-Cre mice with $\mathrm{RelB}^{\text {loxp/loxp }}$ mice to generate nervous system-restricted RelB conditional knockout mice deficient of RelB in astrocytes, oligodendrocytes, neurons, and adult neural progenitors (Fig. 1a). These mice were born with expected Mendelian ratios $\left(50 \% \mathrm{WT}^{\left(\mathrm{RelB}^{\text {loxp} / l o x p}\right)}\right.$ and $50 \% \mathrm{RelB}^{\Delta \mathrm{NP}}$ (nestin-Cre; RelB ${ }^{\text {loxp/loxp }}$ ), were phenotypically normal, and displayed no obvious inflammation or neurological deficits. Surprisingly, $\operatorname{RelB}^{\triangle N P}$ mice had reduced severity of EAE both at initiation and throughout the entire course of the disease
(Fig. 1b, Additional file 1: Figure S1). These mice manifested $\mathrm{EAE}$ at a later day of onset, demonstrated a later day of disease peak, and had a lower peak score compared to WT littermates (Fig. 1c). Although nestin-Cre driver mice display metabolic phenotype [34], the unexpected reduced severity of the EAE in $\operatorname{RelB}^{\triangle N P}$ mice was a result of RelB deletion since EAE severity was comparable in RelB ${ }^{\text {loxp/loxp }}$ mice and nestin-Cre; RelB ${ }^{\mathrm{WT} / \mathrm{WT}}$ mice (Additional file 1: Figure S2). In agreement with lower clinical scores, the $\operatorname{RelB}^{\Delta N P}$ mice also had decreased immune cell infiltration in the white matter of the lumbar spinal cord, particularly along the ventral tracts (Fig. 2a). Decreased meningeal inflammation was also evident. Furthermore, flow cytometry analysis indicated decreased numbers of brain-infiltrating immune cells, including $\mathrm{CD}_{11} \mathrm{~b}^{+}$myeloid cells (both $\mathrm{CD}_{11} \mathrm{~b}^{+} \mathrm{CD} 45^{\text {low }}$ microglia and $\mathrm{CD}_{11} \mathrm{~b}^{+} \mathrm{CD} 45^{\text {high }}$ monocytes), and also $\mathrm{CD}^{+}$and $\mathrm{CD}^{+} \mathrm{T}$ cells (Fig. 2b, Additional file 1: Table S1). Since
A

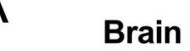

\section{Astrocytes}
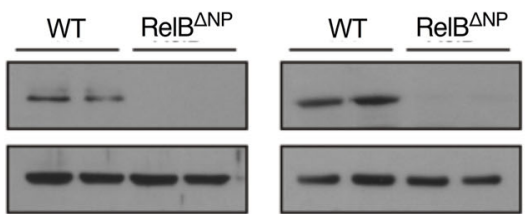

B

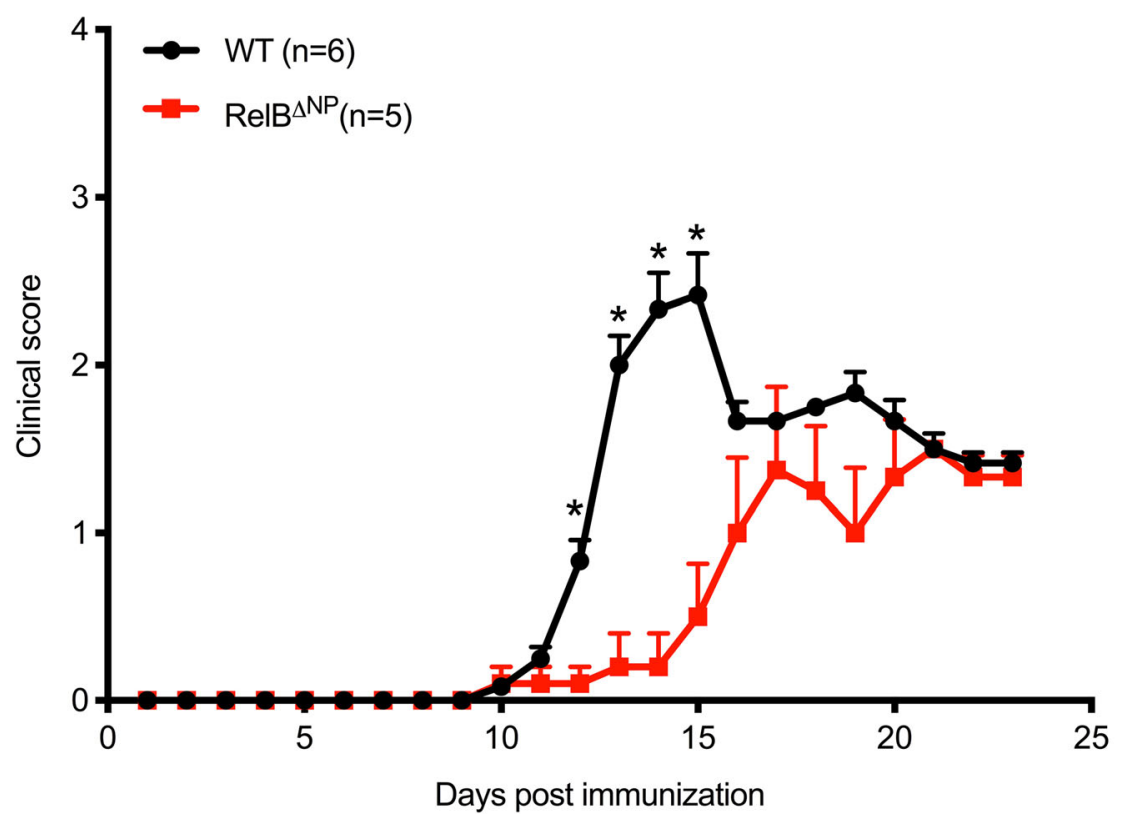

C Spleen WT RelB ${ }^{\Delta N P}$
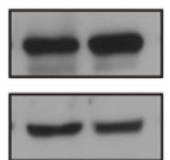

B

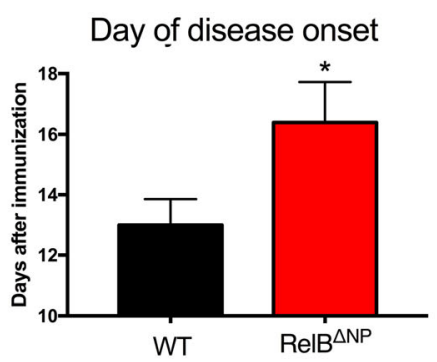

Day of disease peak

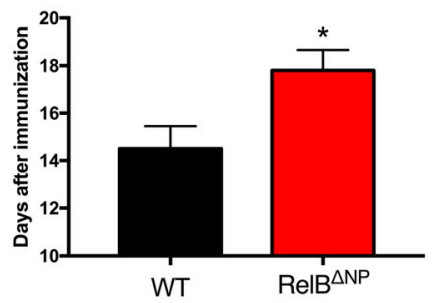

Peak score

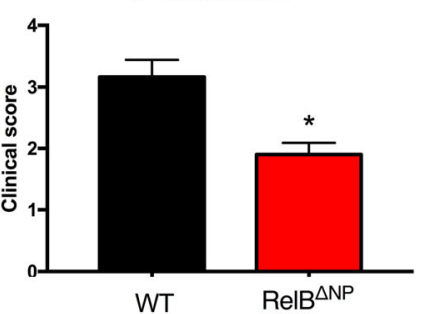

Fig. 1 Ablation of RelB in non-immune CNS cells reduces severity of experimental autoimmune encephalomyelitis. a Deletion of RelB was verified by western blotting in the brains, cultured mouse astrocytes, and spleens from WT (RelB ${ }^{\text {loxP/loxP }}$ ) and RelB ${ }^{\Delta N P}$ mice. $\mathbf{b}, \mathbf{c} E A E$ was induced and clinical scores were recorded for 23 days. $n=5-6$ mice per group. b Multiple $T$ tests $\left({ }^{*} p<0.05\right)$. c $T$ tests: day of onset $(F=4.54, p=0.038)$; day of peak $(F=11.50, p=0.036)$; peak score $(F=13.20, p=0.047)$ 


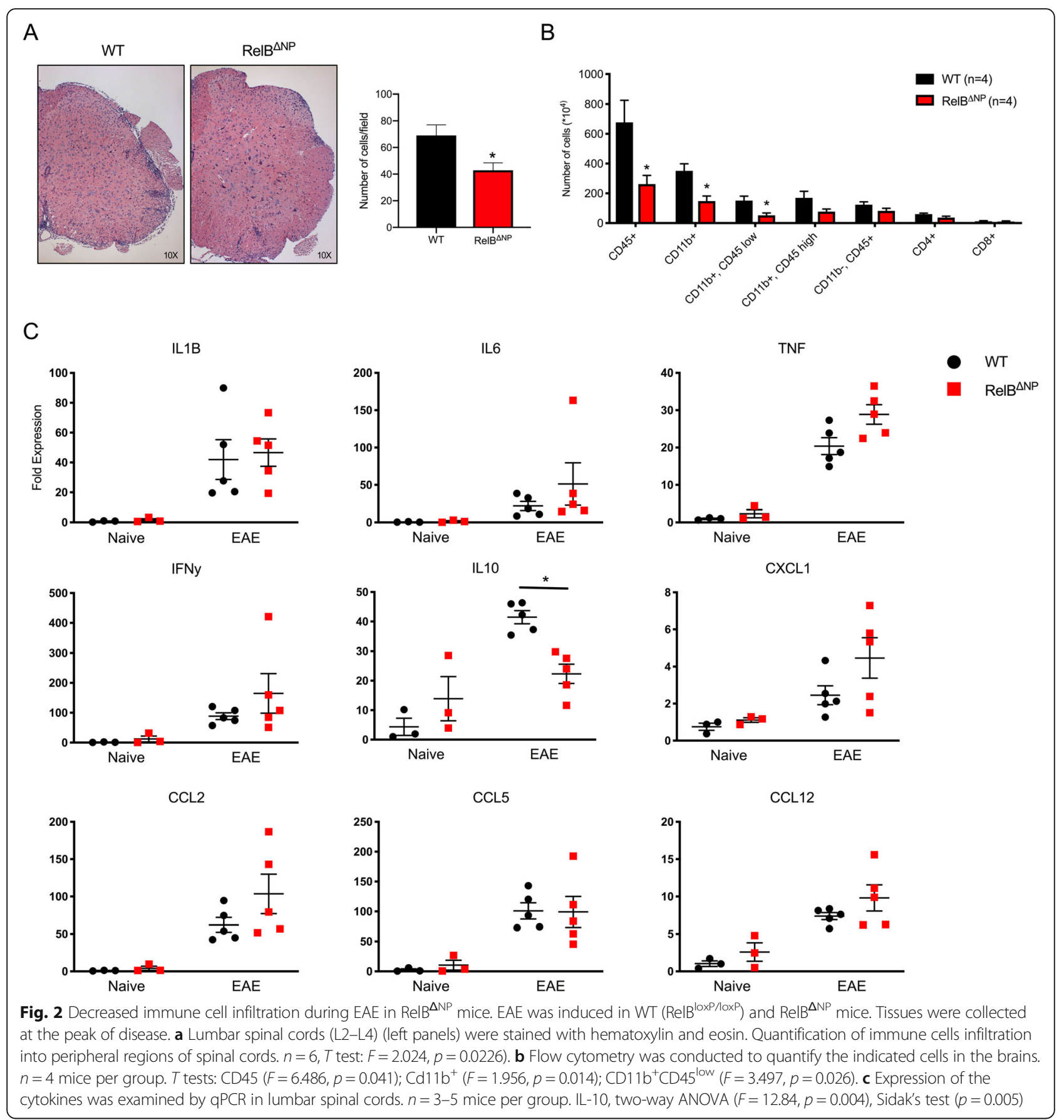

RelB negatively regulates cytokine expression in many cell types [35], including astrocytes [24], we examined cytokine mRNA levels in the spinal cords during EAE. RelB ${ }^{\Delta N P}$ mice expressed anti-inflammatory IL-10 at lower level (Fig. 2c); however, expression of many proinflammatory cytokine and chemokine mRNAs were only incrementally increased in $\operatorname{RelB}^{\Delta N P}$ mice in comparison to $\mathrm{RelB}^{\text {loxp/loxp }}$ littermates. Thus, although deletion of RelB in the non-immune CNS cells slightly enhances cytokine expression during EAE, paradoxically RelB in these cells is protective.
Astrocytic RelB has a limited effect on the severity of EAE Since knockout of RelB in non-immune CNS cells reduced severity of EAE, we sought to determine which cell type is contributing to this phenotype. Astrocytes are critical regulators of immune and inflammatory responses in the brain [36], and they upregulate expression of RelB during EAE [33]. To determine if astrocytic RelB regulates the severity of the disease, we used recently generated $\mathrm{RelB}^{\Delta \mathrm{AST}}$ mice [24] and their RelB ${ }^{\text {loxp/loxp }}$ littermates in EAE experiments. The RelB ${ }^{\triangle A S T}$ mice are phenotypically 
normal and are generated with the expected Mendelian distribution. Although the onset of EAE in RelB ${ }^{\triangle A S T}$ mice was delayed in comparison to WT littermates (Fig. 3a), the severity of EAE (peak score and day of disease peak) was similar (Fig. 3b). In concordance with the similar disease severity, both $\operatorname{RelB}^{\triangle \mathrm{AST}}$ mice and WT littermates demonstrated a similar level of diffuse inflammatory cell infiltrate in the lumbar spinal cord, as well as some focal areas of immune cell infiltration in the white matter (Fig. 3c). We concluded that astrocytic RelB cannot account for the protective phenotype of RelB ${ }^{\Delta \mathrm{NP}}$ mice, suggesting that RelB plays critical protective role in another cell type.

\section{Deletion of RelB in oligodendrocytes attenuates EAE disease severity}

Because death of oligodendrocytes is a hallmark of both MS and EAE [37-39], we asked whether deletion of RelB in oligodendrocytes could explain the reduced EAE severity in $\mathrm{RelB}^{\Delta \mathrm{NP}}$ mice. We generated oligodendrocyte- specific RelB conditional knockout mice $\left(\operatorname{RelB}^{\Delta \mathrm{OLIGO}}\right)$ by crossing RelB ${ }^{\text {loxp/loxp }}$ mice with CNPase-Cre driver mice. The RelB ${ }^{\Delta \mathrm{OLIGO}}$ mice were phenotypically normal and generated progeny as expected. RelB was efficiently deleted from oligodendrocytes since it no longer was detected in CC1-positive cells of RelB ${ }^{\Delta \mathrm{OLIGO}}$ mice, but it was present in CC1-positive cells of WT littermates (Fig. 4a). Interestingly, induction of EAE in $\operatorname{RelB}^{\triangle \mathrm{OLIGO}}$ mice resulted in reduced severity of the disease in comparison to WT littermates (Fig. 4b). Similar to RelB ${ }^{\Delta N P}$ mice, RelB ${ }^{\triangle \mathrm{OLIGO}}$ mice had a lower peak score and later day of disease onset (Fig. 4c); however, the day of disease peak was not affected. The decreased severity of the EAE in RelB ${ }^{\triangle O L I G O}$ mice correlated with a decrease in diffuse inflammatory cell infiltrate throughout the lumbar spinal cord with small scattered focal areas of inflammation (Fig. 4d). There was also a trending decrease in immune cell infiltration in the brain as detected by flow cytometry, which was particularly evident for $\mathrm{CD} 4^{+}$ T cells (Fig. 4e).
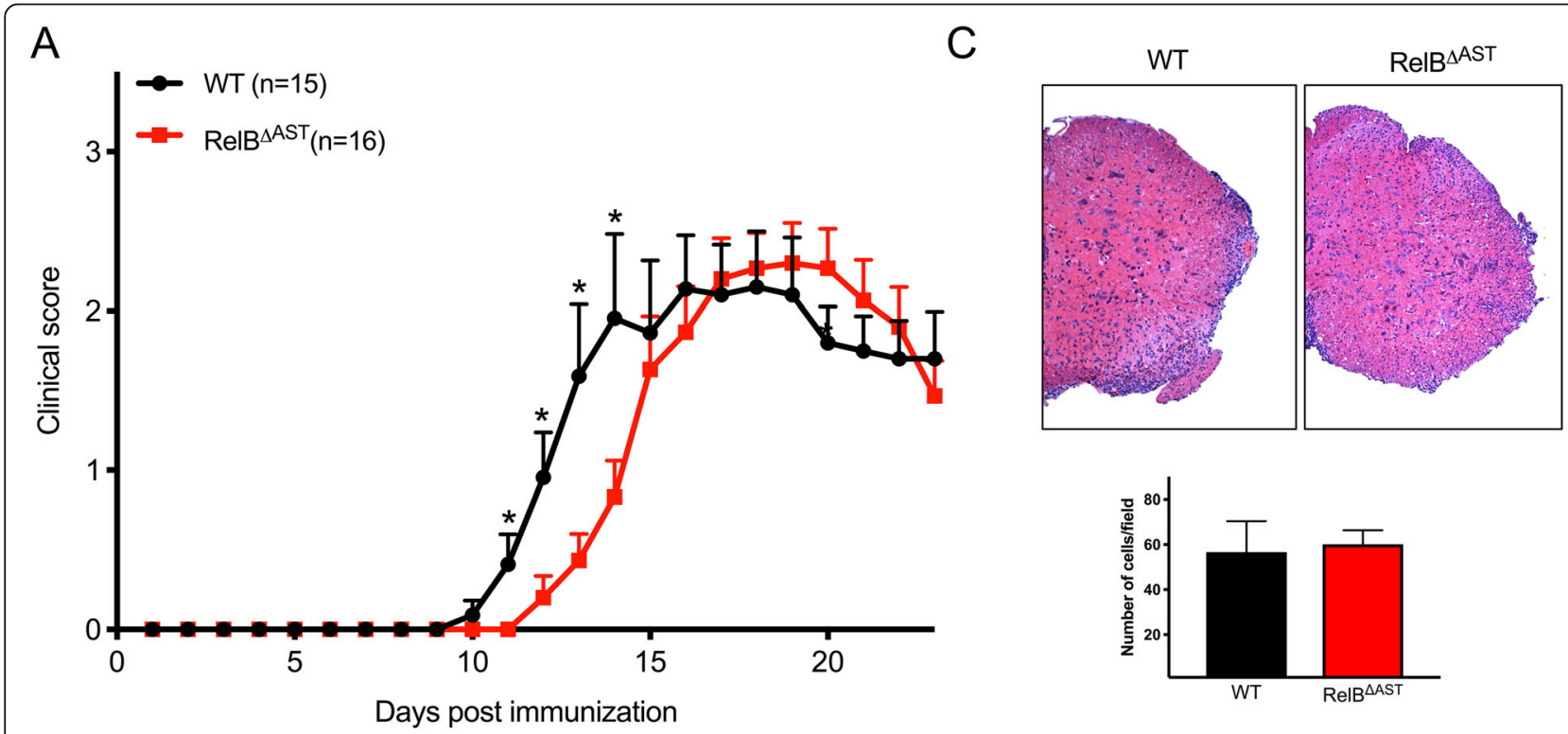

B

Day of disease onset

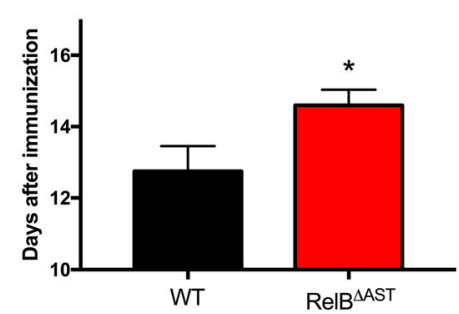

Day of disease peak

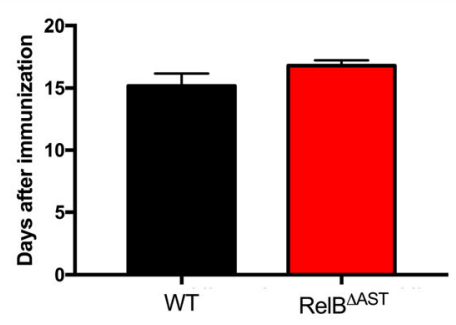

Peak score

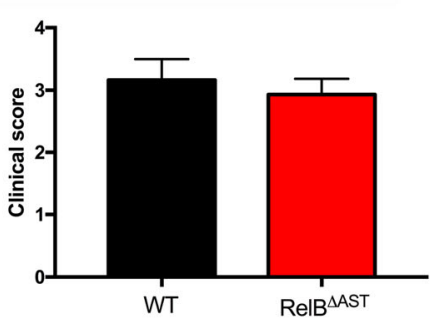

Fig. 3 Astrocyte-restricted ablation of RelB delays the onset of EAE. EAE was induced in WT (RelB ${ }^{\text {loxP/loxP }}$ ) and RelB ${ }^{\triangle A S T}$ mice. $\mathbf{a}$, b Clinical scores were recorded for 24 days. $n=15-16$ mice per group. a Multiple $T$ tests $\left({ }^{*} p<0.05\right)$. b $T$ tests: day of onset $(F=4.274, p=0.013)$; day of peak $(F=2.129, p=0.184)$; peak score $(F=1.390, p=0.554)$. c At the peak of disease, lumbar spinal cords (L2-L4) (left panels) were stained with hematoxylin and eosin. Quantification of immune cells infiltration into peripheral regions of spinal cords. $n=6, T$ test: $F=4.879, t$ test $p=0.824$ 

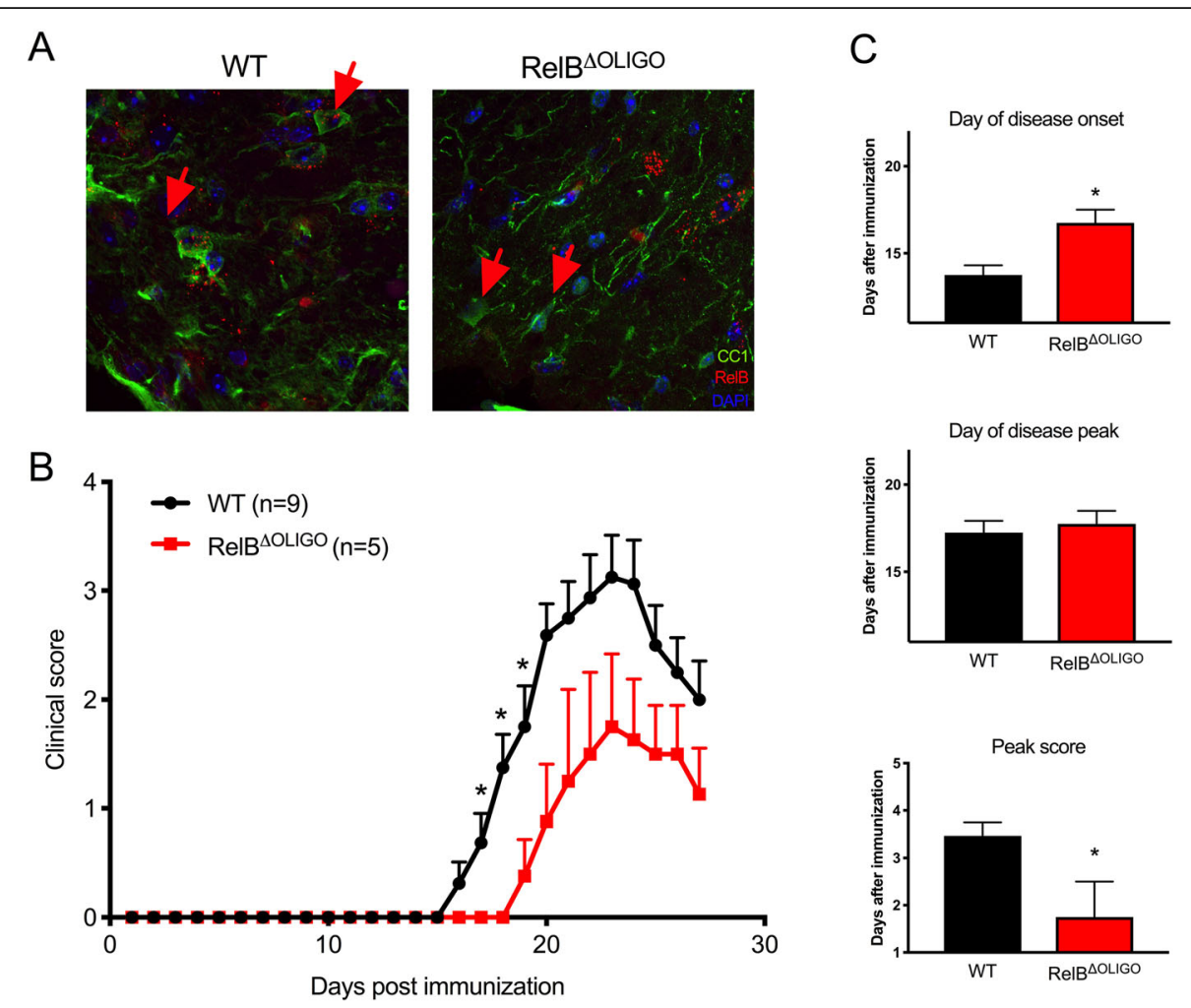

D
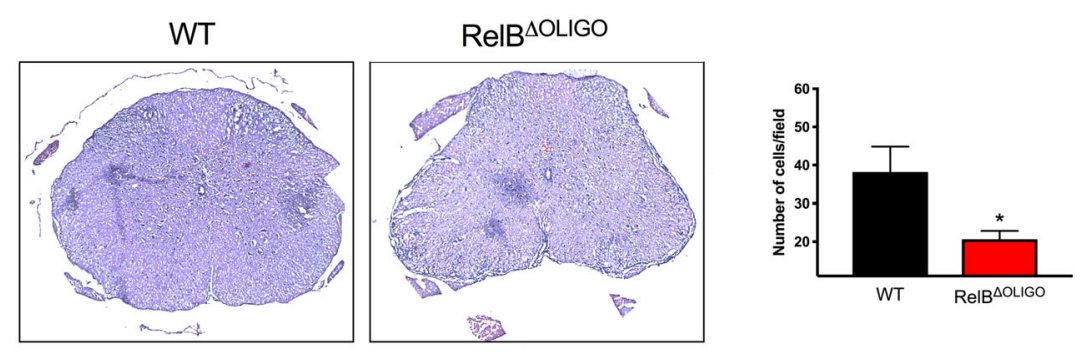

E

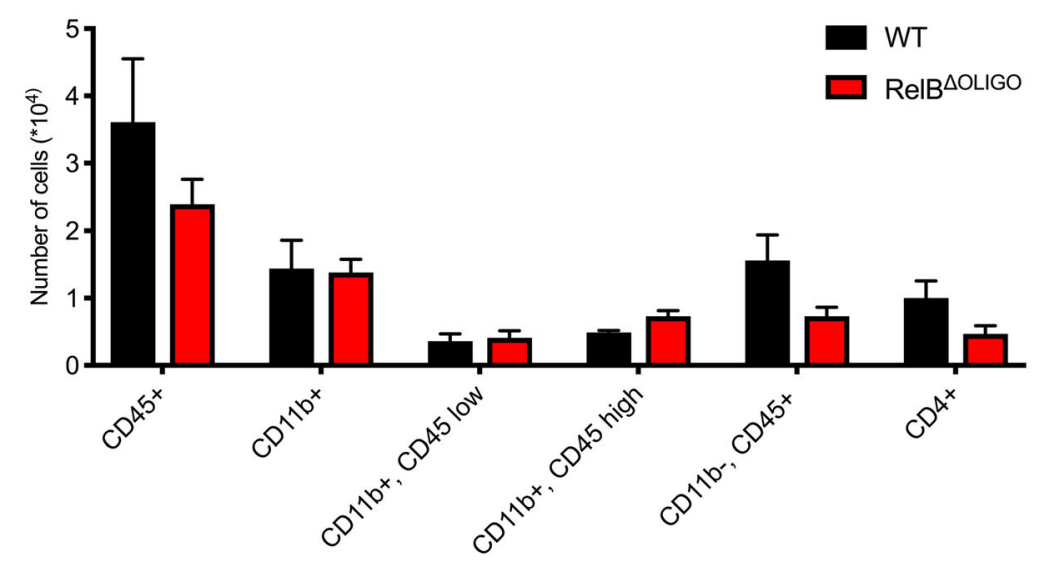

Fig. 4 (See legend on next page.) 
(See figure on previous page.)

Fig. 4 Deletion of RelB in mature oligodendrocytes reduces the severity of EAE. a RelB was visualized in CC1-positive oligodendrocytes in cortical brain sections from WT (RelB ${ }^{\operatorname{loxP} / \text { IoxP }}$ ) and RelB ${ }^{\Delta O L I G O}$ mice by IF. Anti-CC1 and anti-RelB antibodies were used, and sections were counterstained with Hoechst. $\mathbf{b}-\mathbf{e}$ EAE was induced in WT and ReIB ${ }^{\Delta O L I G O}$ mice. $\mathbf{b}, \mathbf{c}$ Clinical scores were recorded for 23 days. $n=5-9$ mice per group. b Multiple $T$ tests $\left({ }^{*} p<0.05\right)$. c $T$ tests: day of onset $(F=1.11, p=0.01)$; day of peak $(F=1.619, p=0.65)$; peak score $(F=3.659, p=0.02)$. $\mathbf{d}$ At the peak of disease, lumbar spinal cords were stained with hematoxylin and eosin ( $L 2-L 4$ ) (left panels). Quantification of immune cells infiltration into peripheral regions of spinal cords. $n=6, T$ test: $F=9.212, p=0.0321$. e Flow cytometry was conducted to quantify the indicated cells in the brains. $n=3-4$ mice per group, $T$ tests

\section{Oligodendrocyte-restricted ablation of RelB prevents demyelination and decreases loss of mature oligodendrocytes}

To determine why RelB ${ }^{\Delta \mathrm{OLIGO}}$ mice develop EAE with reduced severity, we first investigated whether the disease correlates with decreased inflammation characterized by lower expression of cytokines. Activated microglia and reactive astrocytes, but not oligodendrocytes, are the major producers of inflammatory mediators during EAE [40]. Not surprisingly, there was no significant difference between expression of many cytokines and chemokines between $\mathrm{RelB}^{\Delta \mathrm{OLIGO}}$ mice and $\mathrm{RelB}^{\text {loxp/loxp }}$ littermates (Fig. 5a). Although expression of major proinflammatory cytokine mRNAs, such as IL- $1 \beta$ and TNF $\alpha$, was comparable, IFN $\gamma$ and IL-10 mRNA levels were interestingly significantly lower in the spinal cords of RelB ${ }^{\triangle \mathrm{OLIGO}}$ mice. In concordance with these findings, numbers of both $\mathrm{Iba}^{+}$myeloid cells (Fig. $5 \mathrm{~b}$ ) and $\mathrm{GFAP}^{+}$reactive astrocytes (Fig. 5c) were significantly diminished in RelB ${ }^{\Delta \text { OLIGO }}$ mice. Furthermore, RelB ${ }^{\Delta \text { OLIGO }}$ mice had a higher intensity of myelin staining in the lumbar spinal cords compared to WT littermates (Fig. 5d). Oligodendrocyte death followed by regeneration from oligodendrocyte progenitor cells (OPCs) is characteristic of EAE and is a determinant of the clinical phenotype of paralysis [30, 41]. Since IFNY is known to induce apoptosis of oligodendrocyte progenitors $[42,43]$, we examined the expression of markers for OPCs (NG2, OLIG2) and mature oligodendrocytes (MBP, PLP). Although levels of IFN $\gamma$ were significantly lower in $\mathrm{RelB}^{\triangle \mathrm{OLIGO}}$ mice (Fig. 5a), expression of NG2 and OLIG2 in the lumbar spinal cords were not changed (Fig. 5e), suggesting similar survival of OPCs. In contrast, RelB ${ }^{\triangle \mathrm{OLIGO}}$ mice were characterized by significantly higher expression of MBP and PLP mRNA in the lumbar spinal cords, indicating that deletion of RelB prevents mature oligodendrocyte loss during EAE (Fig. 5e). Since RelB can inhibit p65 [23, 44, 45] and p65 promotes survival of oligodendrocytes in vitro $[46,47]$ and during EAE [32], we hypothesized that $\operatorname{RelB}^{\Delta \mathrm{OLIGO}}$ mice were protected due to exaggerated activation of p65. To evaluate this, we first analyzed expression and activation of p65 in $\mathrm{CC} 1$-positive mature oligodendrocytes by immunofluorescence. As expected, there was a greater increase in CC1-positive oligodendrocytes in the spinal cords of $\mathrm{RelB}^{\Delta \mathrm{OLIGO}}$ mice than in RelB ${ }^{\text {loxp/loxp }}$ littermates (Fig. 5f), which was consistent with the elevated expression of MBP and PLP (Fig. 5e). These CC1-positive oligodendrocytes were also p65-positive (Fig. 6a). Next, we evaluated phosphorylation of p65 on Serine 536 that correlates with p65 activation [48]. We found that activated, phosphorylated p65 was present in the nuclei of $\mathrm{CC} 1$-positive oligodendrocytes in both $\mathrm{RelB}^{\Delta \mathrm{OLIGO}}$ mice and their WT littermates (Fig. 6b). Importantly, quantification of these data revealed that the percent of CC1-positive cells that costain with p-p65(Ser536) was significantly higher during EAE in RelB ${ }^{\triangle O L I G O}$ mice than in WT littermates (Fig. 6c). These data suggest that activation of p65 in CC1-positive oligodendrocytes is exaggerated in the absence of RelB, promoting survival of mature oligodendrocytes and subsequently limiting severity of EAE in RelB ${ }^{\triangle \mathrm{OLIGO}}$ mice.

\section{Discussion}

RelB has been mostly recognized as a regulator of immune cell development and differentiation that is critical for $\mathrm{B}$ cell homeostasis and establishment of lymph nodes and germinal centers [12]. RelB also regulates osteoclast differentiation [49]. These functions of RelB are controlled by the non-canonical NF-kB pathway and RelB/p52 complexes. In contrast, RelB/p50 complexes have recently been identified as critical targets of the necroptosis-independent RIPK3-dependent pathway, promoting inflammation in dendritic cells [50]. Interestingly, oligodendrocyte death involves both necroptosis and RIP3K activation [51, 52]. Over the past decade, RelB also emerged as a critical negative regulator of inflammatory responses in non-lymphoid cells. Multiple mechanisms by which RelB negatively regulates inflammation have been proposed to date, including inhibition of p65 translocation and binding [23], epigenetic silencing of chromatin [22], and dimer switching [44]. RelB also limits production of inflammatory cytokines and curbs inflammatory memory in astrocytes [24]. Indeed, our data confirm that RelB limits cytokine production in non-immune CNS cells during EAE since $\operatorname{RelB}^{\Delta N P}$ mice have increased proinflammatory and decreased anti-inflammatory cytokine expression. Unexpectedly however, $\operatorname{RelB}^{\Delta \mathrm{NP}}$ mice displayed reduced severity of EAE indicating that RelB plays other important functions that are in fact not related to the control of cytokine production or inflammation. These conclusions are additionally supported by our findings that deletion of RelB in astrocytes, which 


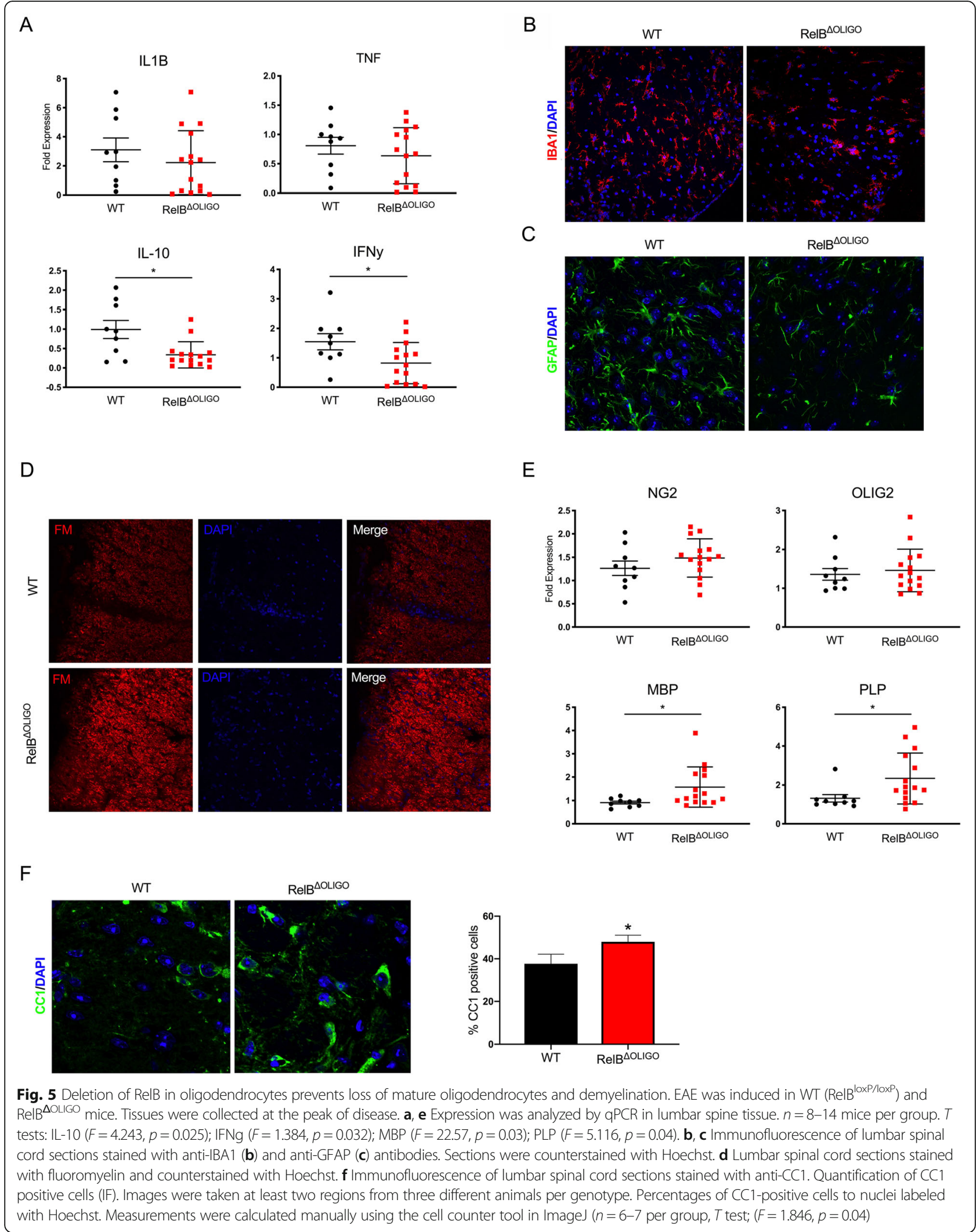




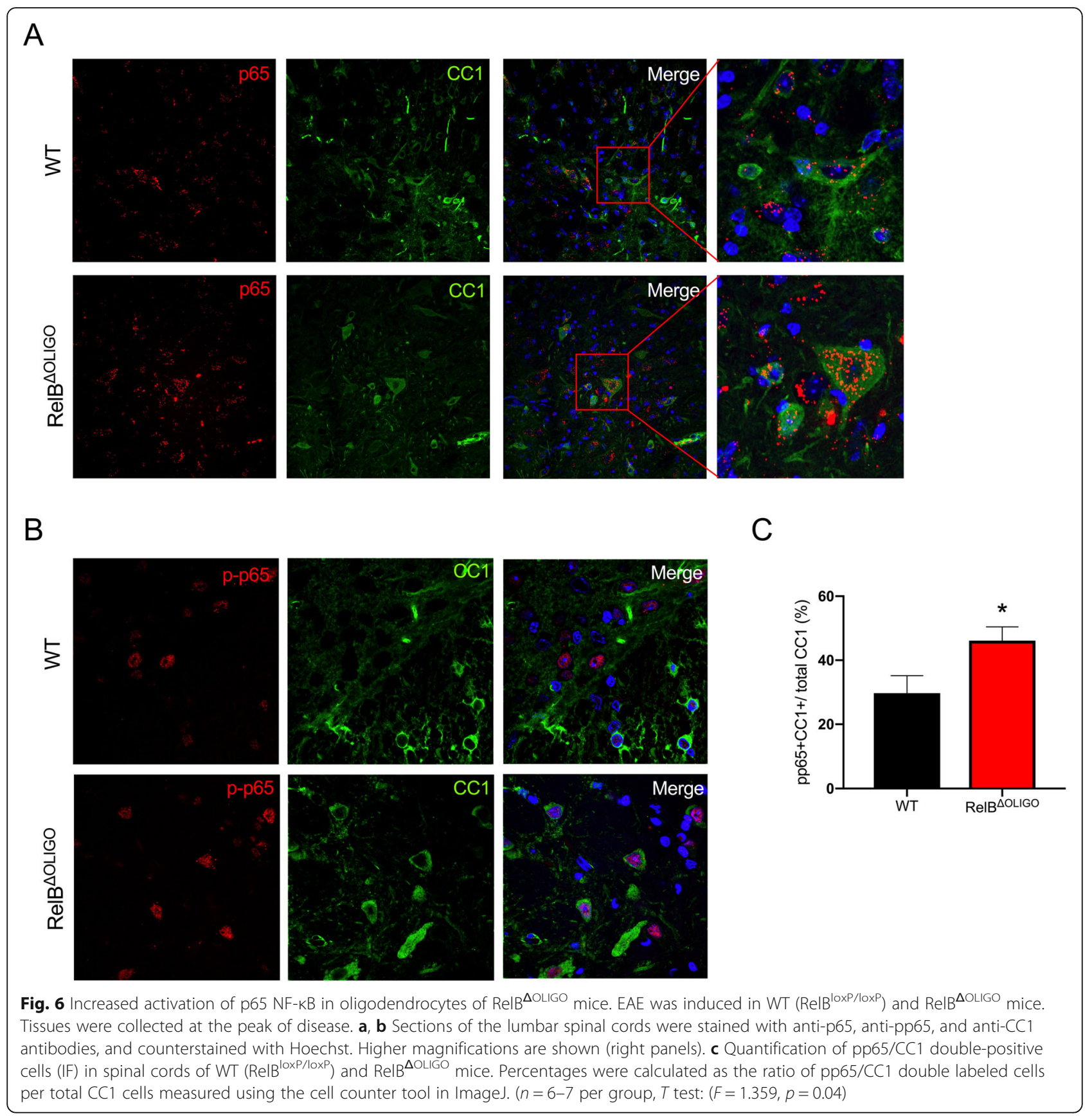

are known to produce substantial quantities of inflammatory cytokines [53], has limited effect on the severity of EAE. Furthermore, although oligodendrocytes are not known to produce significant amounts of cytokines, deletion of RelB in these cells significantly reduced severity of $\mathrm{EAE}$ in RelB ${ }^{\triangle \mathrm{OLIGO}}$ mice. Thus, the protective effect of RelB deletion in non-immune CNS cells during EAE does not seem to be related to its anti-inflammatory functions but rather non-inflammatory effects in oligodendrocytes. Of note, although we did not find a direct correlation between the severity of EAE and expression of proinflammatory mediators, this can be explained by relatively aggressive disease with high cytokine and chemokine expression in both control and RelB-deficient animals.

We found that RelB exhibits deleterious effects in oligodendrocytes, and these cells are the main targets of autoreactive $\mathrm{T}$ cell-mediated response during EAE, which leads to mature oligodendrocyte death, axon degeneration, and increased disease severity $[29,30]$. Although deletion of RelB in CNP-expressing oligodendrocytes decreased the amount of IFN $\gamma$, known to induce apoptosis of OPCs 
during EAE [42, 43], it had no effect on the abundance of oligodendrocyte progenitor markers, suggesting similar survival of OPCs. Nevertheless, enhanced differentiation to mature oligodendrocytes in the absence of RelB cannot be fully excluded. Expression of mature oligodendrocyte markers was significantly higher during EAE in $\mathrm{RelB}^{\Delta \mathrm{O}-}$ LIGO mice. These results suggest that RelB may limit survival of mature oligodendrocytes, promotes their death during EAE, or suppresses differentiation of OPCs.

Previous studies have demonstrated that the canonical activation of $\mathrm{p} 65 / \mathrm{p} 50$ complexes promote oligodendrocyte survival during inflammation [32, 46, 47]. Although the exact mechanism remains elusive, p65 is known to control expression of several anti-apoptotic genes including cIAPs, cFLIP, Bcl-2, Bcl-xL, TRAF1, and TRAF2 [4]. Indeed, we found increased activation of p65 in oligodendrocytes during EAE in RelB ${ }^{\triangle \mathrm{OLIGO}}$ mice. The increased p65 activation in oligodendrocytes can be explained by the lack of RelB-mediated inhibition that is accomplished by previously described mechanisms [22-24, 44]. However, it is also possible that a proposed $\mathrm{p} 100 / \mathrm{І \kappa} B \delta$-mediated crosstalk between canonical and non-canonical NF- $\mathrm{kB}$ pathways [54] regulates p65 activation and thus mature oligodendrocyte survival. Since RelB is known to stabilize $\mathrm{p} 100 / \mathrm{I} \mathrm{KB} \delta$ [55], its deletion may limit the amount of $\mathrm{p} 100 / \mathrm{I} \mathrm{K} B \delta$ in oligodendrocytes and thus indirectly remove $\mathrm{p} 100 / \mathrm{I} \mathrm{kB} \delta$-mediated inhibition of the p65/p50 activation. It is highly probable that all these RelB-dependent mechanisms function in vivo to fine tune inflammation and cell death/survival. Our data suggest that specific targeting of RelB in oligodendrocytes in the future could be explored as a viable option to limit oligodendrocyte loss during MS.

\section{Conclusions}

Overall, our data demonstrate that although RelB suppresses cytokine production by non-immune cells in the CNS, it plays an additional deleterious role in controlling survival of mature oligodendrocytes during EAE. Thus, RelB fine tunes inflammation and cell death/survival during EAE, which potentially could be explored as an option to treat MS in the future.

\section{Additional file}

Additional file 1: Figure S1. Ablation of RelB in non-immune CNS cells reduces severity of EAE. EAE was induced and clinical scores were recorded for 15 days ( $n=15-16$ mice per group, Figure S2. Nestin-driven expression of CRE has no effect on severity of EAE. EAE was induced and clinical scores were recorded for 23 days $\left(n=5-8\right.$ mice per group, ${ }^{*} p<0.05$, T-test). Figure S3. Deletion of RelB in mature oligodendrocytes reduces the severity of EAE. EAE was induced and clinical scores were recorded for 15 days $(n=12-17$ mice per group, ${ }^{*} p<0.05, \mathrm{~T}$-test). Table S1. Infiltration of lymphocytes, $\mathrm{CD} 4+$, and CD8+ cells into brains during EAE. EAE was induced, clinical scores were recorded, and flow cytometry was conducted to quantify the indicated cells in the brains. $n=4$ mice per group. (PDF $240 \mathrm{~kb}$ )

\section{Abbreviations}

CNS: Central nervous system; EAE: Experimental autoimmune encephalomyelitis; IKBa: Inhibitor of NF-kB alpha; MS: Multiple sclerosis; NF-KB: Nuclear factor kappa B; OPC: Oligodendrocyte precursor cells; p50: Nuclear factor kappa B p50 subunit; p52: Nuclear factor kappa B p52 subunit; p65: Nuclear factor kappa B p65 subunit (RelA); RelB: Transcription factor RelB

\section{Acknowledgements}

Not applicable.

\section{Authors' contributions}

ASG planned and performed most experiments, with assistance from DDB, $L B, K M, A H$, and MM. US created RelB ${ }^{\text {loxP } / \text { IoxP }}$ mice and edited the manuscript. TK conceived the study and contributed to planning of the experiments. TK and ASG drafted the manuscript. All authors read and approved the final manuscript.

\section{Funding}

This work was supported by NIH grants R21NS100698, R21NS102802, and R01Al093718 (to T.K.) and by the Intramural Research Program of the NIAID/ $\mathrm{NIH}$ (to U.S). ASG was supported by the F30CA203447 fellowships from the $\mathrm{NIH}$. Microscopy was performed at the VCU Microscopy Facility, supported, in part, by funding from NIH-NCl Cancer Center Support Grant P30 CA016059. Authors state no conflict of interest.

\section{Availability of data and materials}

Information regarding the experimental methods used, and the data in this paper are available to scientific communities upon direct contact to the authors. Individual requests for shipment of mice to AAALAC accredited institutions will be honored. An appropriately signed MTA will be required, as well as permission from original sources of RelB ${ }^{\text {Loxp/LoxP }}$ mice $(\mathrm{NIH})$.

\section{Ethics approval}

Mice were housed at Virginia Commonwealth University according to guidelines of the Institutional Animal Care and Use Committee (IACUC). The mouse protocols were approved by IACUC.

\section{Consent for publication}

Not applicable.

\section{Competing interests}

The authors declare that they have no competing interests.

\section{Author details}

${ }^{1}$ Department of Biochemistry and Molecular Biology, Virginia Commonwealth University, School of Medicine and the Massey Cancer Center, Richmond, VA 23298, USA. ${ }^{2}$ Laboratory of Molecular Immunology, National Institutes of Allergy and Infectious Diseases, National Institutes of Health, Bethesda, MD 20892, USA.

Received: 20 May 2019 Accepted: 17 July 2019

Published online: 30 July 2019

References

1. McQualter JL, Bernard CC. Multiple sclerosis: a battle between destruction and repair. J Neurochem. 2007;100(2):295-306.

2. Lucchinetti C, Bruck W, Noseworthy J. Multiple sclerosis: recent developments in neuropathology, pathogenesis, magnetic resonance imaging studies and treatment. Curr Opin Neurol. 2001;14(3):259-69.

3. Hoffmann A, Natoli G, Ghosh G. Transcriptional regulation via the NFkappaB signaling module. Oncogene. 2006;25(51):6706-16.

4. Karin M, Lin A. NF-kappaB at the crossroads of life and death. Nat Immunol. 2002;3(3):221-7.

5. Shih VF, Tsui R, Caldwell A, Hoffmann A. A single NFkappaB system for both canonical and non-canonical signaling. Cell Res. 2011;21(1):86-102.

6. Gveric D, Kaltschmidt C, Cuzner ML, Newcombe J. Transcription factor NFkappaB and inhibitor I kappaBalpha are localized in macrophages in active multiple sclerosis lesions. J Neuropathol Exp Neurol. 1998;57(2):168-78.

7. Pahan K, Schmid M. Activation of nuclear factor-kB in the spinal cord of experimental allergic encephalomyelitis. Neurosci Lett. 2000;287(1):17-20. 
8. Lock C, Hermans G, Pedotti R, Brendolan A, Schadt E, Garren H, et al. Genemicroarray analysis of multiple sclerosis lesions yields new targets validated in autoimmune encephalomyelitis. Nat Med. 2002;8(5):500-8.

9. Hwang I, Ha D, Ahn G, Park E, Joo H, Jee Y. Experimental autoimmune encephalomyelitis: association with mutual regulation of RelA (p65)/NFkappaB and phospho-lkappaB in the CNS. Biochem Biophys Res Commun. 2011;411(2):464-70.

10. Chen G, Hardy K, Pagler E, Ma L, Lee S, Gerondakis S, et al. The NFkappaB transcription factor c-Rel is required for Th17 effector cell development in experimental autoimmune encephalomyelitis. J Immunol. 2011;187(9):4483-91.

11. Burkly L, Hession C, Ogata L, Reilly C, Marconi LA, Olson D, et al. Expression of relB is required for the development of thymic medulla and dendritic cells. Nature. 1995;373(6514):531-6.

12. Yilmaz ZB, Weih DS, Sivakumar $V$, Weih $F$. RelB is required for Peyer's patch development: differential regulation of p52-RelB by lymphotoxin and TNF. EMBO J. 2003;22(1):121-30.

13. Shih VF, Davis-Turak J, Macal M, Huang JQ, Ponomarenko J, Kearns JD, et al. Control of RelB during dendritic cell activation integrates canonical and noncanonical NF-kappaB pathways. Nat Immunol. 2012;13(12):1162-70.

14. Bhardwaj R, Yester JW, Singh SK, Biswas DD, Surace MJ, Waters MR, et al. RelB/p50 complexes regulate cytokine-induced YKL-40 expression. J Immunol. 2015;194(6):2862-70.

15. Solan NJ, Miyoshi H, Carmona EM, Bren GD, Paya CV. RelB cellular regulation and transcriptional activity are regulated by p100. J Biol Chem. 2002;277(2):1405-18.

16. Gerondakis S, Grumont R, Gugasyan R, Wong L, Isomura I, Ho W, et al. Unravelling the complexities of the NF-kappaB signalling pathway using mouse knockout and transgenic models. Oncogene. 2006;25(51):6781-99.

17. Barton D, HogenEsch H, Weih F. Mice lacking the transcription factor RelB develop T cell-dependent skin lesions similar to human atopic dermatitis. Eur J Immunol. 2000;30(8):2323-32.

18. Weih DS, Yilmaz ZB, Weih F. Essential role of RelB in germinal center and marginal zone formation and proper expression of homing chemokines. J Immunol. 2001;167(4):1909-19.

19. Naspetti M, Aurrand-Lions M, DeKoning J, Malissen M, Galland F, Lo D, et al. Thymocytes and RelB-dependent medullary epithelial cells provide growthpromoting and organization signals, respectively, to thymic medullary stromal cells. Eur J Immunol. 1997;27(6):1392-7.

20. Jacque E, Tchenio T, Piton G, Romeo PH, Baud V. RelA repression of RelB activity induces selective gene activation downstream of TNF receptors. Proc Natl Acad Sci U S A. 2005;102(41):14635-40.

21. Kiebala M, Polesskaya O, Yao Z, Perry SW, Maggirwar SB. Nuclear factorkappa B family member RelB inhibits human immunodeficiency virusTat-induced tumor necrosis factor-alpha production. PLoS One. 2010; 5(7):e11875.

22. Yoza BK, Hu JY, Cousart SL, Forrest LM, McCall CE. Induction of RelB participates in endotoxin tolerance. J Immunol. 2006;177(6):4080-5.

23. Marienfeld R, May MJ, Berberich I, Serfling E, Ghosh S, Neumann M. RelB forms transcriptionally inactive complexes with RelA/p65. J Biol Chem. 2003; 278(22):19852-60.

24. Gupta AS, Waters MR, Biswas DD, Brown LN, Surace MJ, Floros C, et al. RelB controls adaptive responses of astrocytes during sterile inflammation. Glia. 2019;67(8):1449-61.

25. Wang Y, Zhou CF. Involvement of interferon-gamma and its receptor in the activation of astrocytes in the mouse hippocampus following entorhinal deafferentation. Glia. 2005;50(1):56-65.

26. Kang Z, Altuntas CZ, Gulen MF, Liu C, Giltiay N, Qin H, et al. Astrocyterestricted ablation of interleukin-17-induced Act1-mediated signaling ameliorates autoimmune encephalomyelitis. Immunity. 2010;32(3):414-25.

27. Qian Y, Liu C, Hartupee J, Altuntas CZ, Gulen MF, Jane-Wit D, et al. The adaptor Act1 is required for interleukin 17-dependent signaling associated with autoimmune and inflammatory disease. Nat Immunol. 2007;8(3):247-56

28. Brambilla R, Persaud T, Hu X, Karmally S, Shestopalov VI, Dvoriantchikova G, et al. Transgenic inhibition of astroglial NF-kappa B improves functional outcome in experimental autoimmune encephalomyelitis by suppressing chronic central nervous system inflammation. J Immunol. 2009;182(5):2628-40.

29. Prineas JW, Parratt JD. Oligodendrocytes and the early multiple sclerosis lesion. Ann Neurol. 2012;72(1):18-31.
30. Hisahara S, Okano H, Miura M. Caspase-mediated oligodendrocyte cell death in the pathogenesis of autoimmune demyelination. Neurosci Res. 2003;46(4):387-97.

31. Lin W, Lin Y, Li J, Fenstermaker AG, Way SW, Clayton B, et al. Oligodendrocyte-specific activation of PERK signaling protects mice against experimental autoimmune encephalomyelitis. J Neurosci. 2013; 33(14):5980-91.

32. Stone S, Jamison S, Yue Y, Durose W, Schmidt-Ullrich R, Lin W. NF-kappaB activation protects oligodendrocytes against inflammation. J Neurosci. 2017; 37(38):9332-44.

33. Mayo L, Trauger SA, Blain M, Nadeau M, Patel B, Alvarez Jl, et al. Regulation of astrocyte activation by glycolipids drives chronic CNS inflammation. Nat Med. 2014:20(10):1147-56.

34. Harno E, Cottrell EC, White A. Metabolic pitfalls of CNS Cre-based technology. Cell Metab. 2013;18(1):21-8.

35. Tully JE, Nolin JD, Guala AS, Hoffman SM, Roberson EC, Lahue KG, et al. Cooperation between classical and alternative NF-kappaB pathways regulates proinflammatory responses in epithelial cells. Am J Respir Cell Mol Biol. 2012;47(4):497-508.

36. Claycomb Kl, Johnson KM, Winokur PN, Sacino AV, Crocker SJ. Astrocyte regulation of CNS inflammation and remyelination. Brain Sci. 2013;3(3):1109-27.

37. Dowling P, Husar W, Menonna J, Donnenfeld H, Cook S, Sidhu M. Cell death and birth in multiple sclerosis brain. J Neurol Sci. 1997;149(1):1-11.

38. Wolswijk G. Oligodendrocyte survival, loss and birth in lesions of chronicstage multiple sclerosis. Brain. 2000;123(Pt 1):105-15.

39. Pender MP, Nguyen KB, McCombe PA, Kerr JF. Apoptosis in the nervous system in experimental allergic encephalomyelitis. J Neurol Sci. 1991;104(1):81-7.

40. Schmitz T, Chew LJ. Cytokines and myelination in the central nervous system. ScientificWorldJournal. 2008;8:1119-47.

41. Mc Guire C, Volckaert T, Wolke U, Sze M, de Rycke R, Waisman A, et al. Oligodendrocyte-specific FADD deletion protects mice from autoimmune-mediated demyelination. J Immunol. 2010;185(12):7646-53.

42. Itoh $T$, Horiuchi $M$, Itoh A. Interferon-triggered transcriptional cascades in the oligodendroglial lineage: a comparison of induction of $\mathrm{MHC}$ class II antigen between oligodendroglial progenitor cells and mature oligodendrocytes. J Neuroimmunol. 2009;212(1-2):53-64.

43. Horiuchi $M$, Itoh $A$, Pleasure D, Ozato K, Itoh T. Cooperative contributions of interferon regulatory factor 1 (IRF1) and IRF8 to interferon-gamma-mediated cytotoxic effects on oligodendroglial progenitor cells. J Neuroinflammation. 2011;8:8.

44. Saccani S, Pantano S, Natoli G. Modulation of NF-kappaB activity by exchange of dimers. Mol Cell. 2003;11(6):1563-74.

45. Chen X, El Gazzar M, Yoza BK, McCall CE. The NF-kappaB factor RelB and histone $\mathrm{H3}$ lysine methyltransferase G9a directly interact to generate epigenetic silencing in endotoxin tolerance. J Biol Chem. 2009;284(41):27857-65.

46. Nicholas RS, Wing MG, Compston A. Nonactivated microglia promote oligodendrocyte precursor survival and maturation through the transcription factor NF-kappa B. Eur J Neurosci. 2001:13(5):959-67.

47. Hamanoue M, Yoshioka A, Ohashi T, Eto Y, Takamatsu K. NF-kappaB prevents TNF-alpha-induced apoptosis in an oligodendrocyte cell line. Neurochem Res. 2004;29(8):1571-6.

48. Mattioli I, Sebald A, Bucher C, Charles RP, Nakano H, Doi T, et al. Transient and selective NF-kappa B p65 serine 536 phosphorylation induced by $T$ cell costimulation is mediated by I kappa B kinase beta and controls the kinetics of p65 nuclear import. J Immunol. 2004; 172(10):6336-44.

49. Vaira S, Johnson T, Hirbe AC, Alhawagri M, Anwisye I, Sammut B, et al. RelB is the NF-kappaB subunit downstream of NIK responsible for osteoclast differentiation. Proc Natl Acad Sci U S A. 2008;105(10): 3897-902.

50. Moriwaki K, Balaji S, McQuade T, Malhotra N, Kang J, Chan FK. The necroptosis adaptor RIPK3 promotes injury-induced cytokine expression and tissue repair. Immunity. 2014;41(4):567-78.

51. Ofengeim $D$, Ito $Y$, Najafov A, Zhang $Y$, Shan B, DeWitt JP, et al. Activation of necroptosis in multiple sclerosis. Cell Rep. 2015;10(11):1836-49.

52. Yuan J, Amin P, Ofengeim D. Necroptosis and RIPK1-mediated neuroinflammation in CNS diseases. Nat Rev Neurosci. 2019;20(1):19-33. 
53. Liddelow SA, Barres BA. Reactive astrocytes: production, function, and therapeutic potential. Immunity. 2017;46(6):957-67.

54. Shih VF, Kearns JD, Basak S, Savinova OV, Ghosh G, Hoffmann A. Kinetic control of negative feedback regulators of NF-kappaB/RelA determines their pathogen- and cytokine-receptor signaling specificity. Proc Natl Acad Sci U S A. 2009;106(24):9619-24.

55. Maier HJ, Marienfeld R, Wirth T, Baumann B. Critical role of RelB serine 368 for dimerization and p100 stabilization. J Biol Chem. 2003;278(40):39242-50.

\section{Publisher's Note}

Springer Nature remains neutral with regard to jurisdictional claims in published maps and institutional affiliations.

Ready to submit your research? Choose BMC and benefit from:

- fast, convenient online submission

- thorough peer review by experienced researchers in your field

- rapid publication on acceptance

- support for research data, including large and complex data types

- gold Open Access which fosters wider collaboration and increased citations

- maximum visibility for your research: over $100 \mathrm{M}$ website views per year

At $\mathrm{BMC}$, research is always in progress.

Learn more biomedcentral.com/submissions 